\title{
Individual's recollections of their experiences and understanding of their eye condition: results from a survey of visually impaired people in Britain
}

[Accepted for publication: Ophthalmic and Physiological Optics:

Douglas, G., Pavey, S., Corcoran, C. and Eperjesi, F. (2010). Individuals' recollections of the experiences in eye clinics and understanding of their eye condition: results from a survey of visually impaired people in Britain. Ophthalmic and Physiological Optics, 30, 6, 748757]

Graeme Douglas $^{* 1}$, Sue Pavey ${ }^{1}$, Christine Corcoran $^{1}$ and Frank Eperjesi ${ }^{2}$

${ }^{1}$ Visual Impairment Centre for Teaching and Research (VICTAR), University of Birmingham, UK

${ }^{2}$ Ophthalmic Research Group, School of Life and Health Sciences, Aston University, UK

* Corresponding author: VICTAR, School of Education, University of Birmingham, Birmingham, B15 2TT, UK. e-mail address: g.g.a.douglas@bham.ac.uk

\begin{abstract}
Background/aims. Network 1000 is a UK-based panel survey of a representative sample of adults with registered visual impairment with the aim of gathering information about people's opinions and circumstances. Method. Participants were interviewed (Survey 1: 2005; Survey 2: 2006/07) on a range of topics including the nature of their eye condition, details of other health issues, use of low vision aids (LVAs) and their experiences in eye clinics.

Results. $11 \%$ of people did not know the name of their eye condition. $70 \%$ of participants reported having long-term health problems or disabilities in addition to visual impairment and 43\% reported having hearing difficulties. 71\% reported using LVAs for reading tasks.

Participants who had become registered as visually impaired in the previous eight years $(\mathrm{N}=395)$ were asked questions about non-medical information received in the eye clinic around that time. Reported information received included advice about 'registration' (48\%), low vision aids (45\%) and social care routes (43\%); $17 \%$ reported receiving no information. While $70 \%$ of people were satisfied with the information received, this was lower for those of working age (56\%) compared with retirement age (72\%). Those who recalled receiving additional non-medical information and advice at the time of registration also recalled their experiences more positively. Conclusions. Whilst caution should be applied to the accuracy of recall of past events, the data provides a valuable insight into the types of information and support that visually impaired people feel they would benefit from in the eye clinic.
\end{abstract}

Keywords: visual impairment, survey, registration, eye clinic, satisfaction 


\section{INTRODUCTION}

The general field of social policy and disability has often drawn upon surveys of disabled people to gain a better understanding of their opinions and circumstances, e.g. in the UK Martin et al, (1989) and Williams et al, (2008). Researchers concerned with visual impairment have also carried out similar surveys. For example, the 'Blind and partially sighted adults in Britain: the RNIB Survey' (Bruce et al, 1991) was the first national survey of its kind in the UK, and the DISTAB project sought to use such national surveys to make international comparisons (Hendershot and Crews, 2006). Surveys of visually impaired people provide an opportunity to gather information on a range of topics e.g. perceived health, employment, quality of life and finance. They also provide an opportunity to gather people's views and understanding of aspects of their life that are more closely linked to their vision, including understanding of their vision and their eye conditions, their use of low vision aids (LVAs) and their recollections of experiences in eye clinics. This paper presents data taken from an ongoing survey in relation to some of these issues.

\section{The Network 1000 project}

The UK-based research project entitled 'Network 1000: Surveying the changing needs of visually impaired people’ began in 2004. The ongoing project had a number of key aims. Firstly, the project sought to establish a representative consultation network of approximately 1000 visually impaired people aged 18 and over who could be surveyed on a range of social issues in order to influence service development and provision. A second aim was to adopt a more longitudinal approach to data collection. While cross-sectional surveys such as the one carried out by Bruce et al (1991) have been very influential as a resource to many in the field of visual impairment (researchers, services providers and campaigners), they are expensive to conduct and tend to only gain a limited 'snapshot' of the target population's circumstances and opinions. A longitudinal (or panel) survey design provides opportunities to gather a greater range of data, is able to measure changes in circumstances over time, and is able to respond to topics which have been raised by research participants. So far the project has successfully recruited a sample of participants (all registered as blind and partially sighted in Britain) who have been interviewed twice ('Survey 1' and 'Survey 2').

Finally, the project aimed to provide statistically useful data on the changing views, experiences and needs of visually impaired people that could be used to influence service development and provision. The research has already generated a number of reports and papers on a range of social topics including education (e.g. Pavey et al, 2008), computer use (e.g. Douglas et al, 2007), employment (e.g. Clements et al, 2010), benefit entitlement (e.g. Douglas et al, 2008) and reports making comparisons to the general population (e.g. Clements and Douglas, 2009).

\section{People's understanding of their vision and health}

To some extent asking people for details of their visual impairment (and overall health) is a method of checking if the range and distribution of the reported visual impairments fits with our general understanding gleaned from epidemiological studies. However, given most social surveys involve the use of interviews and/or self-completion questionnaires, they generally do not (and cannot) seek to collect data regarding the precise causes of people's visual impairment (social researchers generally do not have the means of validating people's 
descriptions of their impairment). Therefore, more importantly social surveys give an insight into people's own understanding of their health.

Understanding people's knowledge and interpretation of their visual impairment (and overall health) is important because it gives professionals an insight into the complexities of their client's situations and has implications for communicating with them sensitively and practically. For example, Pollard et al (2003) identified clients' awareness and understanding of their low vision as a barrier to them accessing low vision services. In their survey of members of the UK-based Macular Disease Society, Mitchell et al (2002) concluded that "many people with macular disease have unsatisfactory experiences of the healthcare system", and go on to argue that many reasons for dissatisfaction could be resolved if health care professionals "had a better understanding of and empathy with patient experiences". Although the research is now quite dated, it is interesting that Bruce et al (1991) note that when asked about the cause of their visual problem, "about 1 in 5 people aged 75 and over mentioned nothing more specific than 'ageing' or 'old age' or, very occasionally, 'macular degeneration"”.

More generally, we might expect additional reported health problems amongst visually impaired people given their older age profile compared with the general population. Bruce et al (1991) reported a high incidence of disabilities and long-term health problems amongst their sample and it would be useful to explore this in a more up-to-date study and compare the findings with those of the general population.

In terms of approaches to rehabilitation, there is strong evidence of the effectiveness of LVAs in helping people access print (e.g. Lussenhop and Corn, 2002; Margrain, 2000; Watson et al, 1997). In the UK, the Low Vision Services Consensus Group (1999) made recommendations for future service delivery of low vision rehabilitation (LVR) which seeks to help visually impaired people make best use of their remaining eyesight. These low vision services are conventionally provided by optometrists working in hospital eye clinics, and a primary focus of this work is the provision of and training in the use of LVAs (e.g. Reeves et al, 2004).

\section{Experiences in eye clinics}

The main service given to patients in hospital eye clinics is medical diagnosis, treatment and advice by ophthalmic and optometric professionals. Patients might also receive non-medical support and advice from a range of professionals. There is quite a lot of general literature describing the procedures for giving such non-medical advice and support in eye clinics (e.g. McBride, 2001; NALSVI, 2002). Linked to these developments (and an important and influential source of data) have been articles reflecting people's (often negative) experience of services. These articles are often qualitative in nature, often draw upon participatory/emancipatory methodologies which seek to identify perceived injustice (e.g. Duckett and Pratt, 2001), are usually based upon a small sample size and are sometimes autobiographical (e.g. Dale, 2008; Fourie, 2007). Such articles are powerful because of the directness and richness of their accounts, but they are also limited because it is unclear how typical such accounts are across the population of visually impaired people.

Network 1000 Survey 1 did not ask any direct questions about visually impaired people's experiences in eye clinics. However, through open questions at the end of the interviews the broad topic was raised by many participants (and this is reported in this paper). The strength of a panel survey design (reflected in a key aim of the project as a whole) is that it is able to 
respond to issues raised by participants in one survey wave and collect further information on relevant topics in subsequent waves. For this reason Network 1000 Survey 2 included questions about peoples' recollections of experiences in the eye clinic at the time of certification/registration as blind or partially sighted which had taken place between 1999 and 2005 (up to 8 years prior to the interview). This posed a methodological challenge because studies have shown that patients' recollections of medical consultations can be poor within relatively short time-periods of a consultation (e.g. McGuire, 1996). While accepting this, it is nevertheless important to listen to the 'insider's' perspective (Hammel et al 2008). In this way the service users views can be heard first-hand and, because of this qualitative and somewhat subjective approach, this can often illuminate unexpected perceptions of the services (Angastas, 2004). Whilst these views are often difficult to link with any real accuracy to events in the clinic, they are important nonetheless as they give an insight into patients' understanding of these events.

\section{Aims and purpose}

Drawing upon Network 1000 Survey 1 and 2 data, this article aims to do two things. Firstly, to describe some details of participants' understanding of their visual impairment as well as other related issues linked to their vision, their use of low vision aids and other aspects of their health. Secondly, to explore participants' current use of eye clinics in addition to reporting recollections of their experiences in the eye clinic at the time of certification/registration as blind or partially sighted which had taken place between 1999 and 2005 (up to 8 years prior to the interview).

\section{METHODS}

\section{Sampling}

Crucial to the Network 1000 design was the construction of a representative sample of visually impaired people in Britain.

In Britain, an ophthalmologist can assess whether a person can 'register' as sight impaired (partially sighted) or severely sight impaired (blind). If the visual impairment is of sufficient severity (and with agreement from the visually impaired person) then the ophthalmologist will complete a 'certificate of vision impairment' and send it to the person's local social services department. Similar referral processes exist in other countries (e.g. 'legal blindness' in the USA). The local authorities maintain registers of people who are sight impaired (partially sighted) or severely sight impaired (blind). Approximately 360,000 people are registered as visually impaired in Britain (see Department of Health, 2003; Scottish Executive, 2003; National Assembly for Wales, 2003). Drawing upon the registers as a sampling frame, a two-stage sampling design was adopted. Stage one involved a random sample of 20 local authority Social Services Departments in England (15), Scotland (4) and Wales (1) (probability of selection proportional to the size of the register held by each authority to avoid bias in favour of people in small local authorities). Stage two involved creating a sample of those registered as blind or partially sighted from each selected local authority with weighted stratification by age (with the research targeting 200 participants in each of the five age groups: 18-29, 30-49, 50-64, 65-74, and 75+ years). Approximately 6000 recruitment letters (in large print and audio tape) were sent out inviting people to participate in the project. This led to the recruitment of 1007 participants approximately 
equally split across the age groups. Weighted frequencies from the sample (accounting for age) reflected the expected distribution for gender and registration status (blind and partially sighted). A more detailed account of the sampling process is presented in Corcoran et al (2004), and Douglas et al (2006).

\section{Interviews}

Network 1000 Survey 1 and Survey 2 involved telephone interviews which took an average of 40 and 30 minutes respectively. Survey 1 was carried out in $2005(\mathrm{~N}=1007)$, and Survey 2 approximately 18 months later in 2006/07 ( $N=922$, sample attrition due to participant withdrawal, loss of contact, unavailability, ill health and death).

The structured interview schedules (see Corcoran et al, 2004; Pavey et al, 2005) covered many topics: some topics were longitudinal questions (e.g. employment status, vision) and others were one-off 'theme' questions (e.g. access to services). Some of the interview schedule made use of standard questions taken from other surveys to enable comparison of results (e.g. RNIB Adults Needs Survey; Labour Force Survey; British Social Attitudes Survey; British Household Panel Survey). However, some topics had not been covered in detail in other surveys and new questions were constructed.

Drafts of the interview schedules were commented upon by the project steering group and the final versions were piloted to test for timing and ambiguities. The team of interviewers were all trained to use the schedule (e.g. to read the questions and offer prompts and probes in a standardised format and use the computer assisted interviewing software).

\section{Analysis}

In the first part of the results the analysis focuses upon 960 participants who took part in Survey 1 . The analysis excludes 47 people who had learning and communication difficulties such that the interview schedule was inappropriate (for these people a 'key informant' was interviewed who knew the visually impaired person, see Douglas et al, 2006).

In the second part of the results, we focus the analysis upon 395 participants who had been registered in the preceding eight years and from whom we had collected relevant data (participants may find it too difficult to recollect experiences from longer ago and we were most interested in people's experiences of relatively contemporary services). Given the timings of Surveys 1 and 2, these 395 participants had been certified as blind or partially sighted between 1999 and 2005 and all had been registered between one and eight years prior to the interview.

The results reported are weighted to account for the differences in the age distributions between the stratified sample and population.

\section{SURVEY 1 RESULTS}

\section{Reported eye conditions, vision and other disabilities}

Participants reported having a range of eye conditions which caused their visual impairment (Table 1). As would be expected, these reflect how different conditions are linked to age (e.g. increased reported age-related macular degeneration, glaucoma and cataracts amongst people 
of retirement age). Thirty-two per cent described 'other' eye conditions, as well as $11 \%$ who did not know the name of their eye condition. Both these groups combined (43\%, $N=581$ ) were asked follow-up questions about the nature of their condition and were asked to describe in their own words what was wrong with their eyesight which was noted verbatim by the interviewers. An analysis of this additional information was led by a qualified optometrist (Author 4). The descriptions people gave of their eye conditions enabled categorisation into some recognised visual conditions, but more commonly into 'symptoms' and 'signs' of visual impairment (Table 2).

[Insert Table 1 and Table 2 about here]

Eleven per cent of people did not know the name of their eye condition when questioned. Of those who did name their eye condition, $20 \%$ had to be prompted when they did not spontaneously give the name of their eye condition.

Participants were asked a number of questions about how much they could see using day-today language (Bruce et al, 1991). The variety of responses confirmed that visually impaired people have a range of reported functional vision for a variety of tasks. For example, $18 \%$ of people said they could read ordinary newspaper print when wearing glasses/contact lenses (without using a magnifier of any kind). Margrain (2000) reports a similar figure of 23\% for a sample of low vision clinic patients. In contrast, 30\% reported they could not read any kind of print without a magnifier. Similarly, $4 \%$ reported having no light perception while the majority (91\%) described being able to see the shapes of furniture in a room (or better).

Under half of visually impaired people (39\%) felt that the difficulty they had with their sight was about the same as a year earlier. In contrast, $56 \%$ reported that the difficulty was now greater, whilst $5 \%$ felt their vision had improved. There was a pattern in terms of age, where younger participants were more likely to say it was "about the same" compared to older participants who were more likely to report that the difficulty was greater than it had been a year previously (probably partly linked to older people having more recent and later onset conditions such as age-related macular degeneration).

Almost three quarters (70\%) reported that they had long term health problems or disabilities, other than their visual impairment. The likelihood of this increased by age, with $73 \%$ of those aged 65 and upwards reporting additional health problems or disabilities compared with less than $50 \%$ for those aged under 50 (see Table 3 ). Some of the reported conditions were clearly linked to age as would be expected (e.g. heart problems and arthritis). There is clear evidence that registered visually impaired people are more likely to report having a long term health problem or disability (in addition to their visual impairment) compared with the general population as found in the General Household Survey 2006 (ONS, 2008). Table 3 shows that these differences are more pronounced in younger age groups: in the age group 18-29 years, 46 per cent of visually impaired people report having an additional disability compared to 15 per cent of the general population (a difference of 28 per cent). This difference tends to decrease up the age groups.

[Insert Table 3 about here]

Interestingly, in response to the general question about long-term health problems or disabilities relatively few people identified any hearing difficulty. In contrast, when asked a 
direct question about hearing $43 \%$ reported difficulty (62\% of these described having a hearing aid). Unsurprisingly, reported difficulty with hearing increased with age.

\section{Low vision aids (LVAs)}

Table 4 presents a summary of the use of LVAs for reading: 71\% reported they used magnifiers for reading (23\% did not use LVAs but had in the past, and $7 \%$ had never tried to use an LVA). The likelihood of using an LVA increased with age (53\% in 18-29 age group to $73 \%$ in $75+$ age group). Comparison with the RNIB study (Bruce et al, 1991) suggests a general increase in LVA uptake in the two decades between 1986 and 2005 (64\% reporting using LVAs in the RNIB study which was carried out in 1986-87), and the greatest difference appears to be amongst the working age group. This pattern is also observed for different types of LVA. Interestingly, Closed Circuit Televisions (CCTV, here taken to include cameras attached to a television, and small scanners with a screen for reading labels, as well as more traditional CCTVs) were reported to be possessed by $14 \%$ of participants and this technology was not reported at all in the earlier RNIB study.

[Insert Table 4 about here]

\section{'Any other comments'}

Survey 1 did not include any questions about participants' use of services. However, unusually for a survey of this size, the interview included a final open question which asked participants if they wished to raise any issue which was important to them in relation to their visual impairment. The details of the method and results of the analysis are presented elsewhere (see Douglas et al, 2006 and Douglas et al, 2008) but the rationale for the approach was twofold. While it provided an interesting insight into visually impaired people's views, it also provided a mechanism for generating topics for further (and more standardised) research in Survey 2. The analysis of the enormous amount of qualitative data generated many themes, but of particular relevance to this article was that 122 participants raised issues linked to what was broadly labelled 'counselling, emotional needs and adjustment' which included many people reflecting upon the support they were given at the time of the diagnosis of their visual impairment. Following advice from the project steering group it was decided to include some standard questions in relation to this topic in Survey 2, and it is these results which are presented below.

\section{SURVEY 2 RESULTS}

The following results are taken from Survey 2 and draw upon responses from 395 participants who had been certified as blind or partially sighted between 1999 and 2005; all had been registered between one and eight years prior to the interview.

\section{Current attendance at eye clinics and low vision clinics}

Fifty two per cent of people registered as visually impaired in the preceding eight years reported they were visiting an eye clinic at the time of the survey (that is, an appointment in the last six months, or an arranged appointment in the future). The majority told us that they were visiting the eye clinic for a check up (93\%), and 77\% told us they were there to visit the ophthalmologist. 
Low vision clinics or centres in the UK exist to help people make the best use of their remaining sight and often (but not always) are based within or near an eye clinic. In low vision clinics, it is often optometrists who carry out assessments of functional vision, dispense magnifiers and other low vision aids to visually impaired people, as well as providing advice about lighting and other aspects of vision. Twenty per cent of visually impaired people said they were currently visiting a low vision clinic (a further $29 \%$ had visited one in the past, this gives a total of approximately half of participants who had been registered as blind or partially sighted in the previous eight years who had visited a low vision clinic at some time).

\section{Recollections of certification as visually impaired}

The 395 participants who had been registered as visually impaired in the preceding eight years were asked to think about the time at the eye clinic when they were first certified as visually impaired by their ophthalmologist. Overall, nearly half (48\%) did not recall receiving an explanation of the registration process at the time of certification in the eye clinic. Nevertheless, a range of non-medical information was reportedly given at that time (Table 5), although $17 \%$ described receiving no such information.

[Insert Table 5 about here]

Overall satisfaction (measured on a three point scale: satisfied, partially satisfied and not satisfied) about information received at time of certification was relatively high (70\% saying they were satisfied). Level of satisfaction appears to be associated with age with satisfaction being relatively low for those of working age (56\% compared with $72 \%$ of those of retirement age (aged 65+) reporting overall satisfaction), and this difference was found to be significant $\left(\chi^{2}=10.5, \mathrm{df}=1, \mathrm{p}<0.001\right)$. Perhaps unsurprisingly, level of satisfaction was also significantly associated with recollection of non-medical advice received, with $79 \%$ of people who recalled receiving some sort of advice reporting satisfaction while only $34 \%$ of people who recalled receiving no advice were satisfied $\left(\chi^{2}=53.1, \mathrm{df}=1, \mathrm{p}<0.0005\right)$. Satisfaction was not found to be associated with length of time since registration (between the years of 1999 and 2005, $\chi 2=1.9, \mathrm{df}=5, \mathrm{p}>0.05$ ) suggesting that there was a consistency irrespective of the time gap between registration and interview. Arguably, this also suggests that there was no obvious change in satisfaction about information received at time of certification (increase or decrease) across Britain between 1999 and 2005, although changes in policies in given individual eye clinics would be unlikely to be reflected in the findings from this national sample.

As noted in the introduction, the quality of patients' recall of medical consultations has been found to vary, and of course is highly subjective anyway even if actual events are accurately recalled. However, the data is still valuable in terms of demonstrating what visually impaired people think is important and the sort of support they would value, even if the actual events they recall are not entirely reliable. The discussion section revisits this.

\section{Analysis of explanations}

A follow-up open question collected views about why people expressed these levels of satisfaction. Rather than having a predefined list of possible responses as in the structured questions of the interview schedule, participants were encouraged to describe their satisfaction in their own words and the interviewer recorded what the participant said 
(verbatim if possible). A large number of quotes were generated in response to the question and this was imported into the data analysis tool NVivo (version 7). The data was then analysed following a grounded approach (or 'editing' approach) in which the data is coded in order to draw out the themes (e.g. see Robson, 2002). This involved scrolling through the documents and highlighting text that related to identified themes. Analysis of this qualitative data revealed four overlapping themes:

(a) Emotions. People expressed a variety of emotions when recalling their experiences. The most frequently reported one being that of shock: e.g. "[...] I was shocked at being registered - I thought I could see enough” (female, working age, not satisfied).

(b) Expectations and timing. Unsurprisingly, many of those who were satisfied said they were happy with the support they received or felt that they did not need any. However, with the benefit of hindsight and newly acquired experience of visual impairment, when people looked back to that time they also noted they did not know what to expect and some expressed dissatisfaction with the services they had received: e.g. "You don't really know what there is and what you need to know - it's things you find out later that makes you wonder why you weren't told things" (male, working age, unsure of his satisfaction). Linked to this is that information often needs to be given using a stepped approach (particularly given the shock people may be feeling and the complex situation in which they find themselves): e.g. "Initially I felt they had tried to explain, but then when I needed answers later on it was difficult to get hold of somebody" (female, working age, satisfied).

(c) Contact with the medical professionals at the eye clinic. People described both positive and negative interactions with staff within eye clinics. Positive comments included the helpfulness of doctors, nurses and optometrists: e.g. "I thought they were really good. The woman there was really good, she understood what I was saying which is everything" (female, retirement age, satisfied). Negative comments included examples of insensitivity and difficulty understanding medical language: e.g. "The first doctor I went to on my own - I couldn't understand the big words they used” (male, working age, partly satisfied).

(d) Support or information at the eye clinic. Some participants described the kind of help that they thought had been or would be most useful. Many referred to types of services presented in Table 5. There were a number of comments which highlighted that some people felt dissatisfied that the eye clinic did little beyond diagnosis: e.g. "I didn't really have any help from the hospital, just diagnosed the condition and said there wasn't much to be done" (female, retirement age, not satisfied). Nevertheless, other examples highlight that when implemented sensitively and appropriately eye clinics and social support services can link together effectively: e.g. "When [I lost my eyesight I was all on my own], but social services and the eye clinic were marvellous" (female, retirement age, satisfied).

\section{DISCUSSION}

The results from Survey 1 provide evidence that people registered as visually impaired often have disabilities and long-term health problems in addition to their visual impairment. This is associated with age generally, however irrespective of this it was found to be more common amongst visually impaired people than the general population.

In their reflections upon their experience in the eye clinic, some participants highlighted the way they were spoken to as a key issue - some feeling that staff were cold or dismissive, 
others feeling that they found it hard to understand what was being described. This poor communication experienced by some may be linked to the finding that over $20 \%$ of people were unable to recall the name of their eye condition. The challenge of professionals having to explain complex information is no doubt increased as the patients are often in a state of shock having received bad news, and this may be compounded further as many also have health and/or communication difficulties in addition to their visual impairment (70\% reporting this to be the case, and many reported hearing difficulties). Possible other evidence for this difficulty was found in a recent study of patients attending a hospital-based glaucoma clinic which noted that poor compliance with medication was significantly higher in those with hearing loss (Wallace et al, 2008).

Another key issue highlighted was the importance of the eye clinic in providing visually impaired people with a broad range of information in addition to clear details about their medical condition. Depending upon timing, this information might include information about other services such as low vision services, voluntary and statutory social care services, information about equipment, and emotional support.

Registration as blind or partially sighted in the UK is one of the formal ways of linking medical services to social care services and it is important that ophthalmologists understand and communicate this. Nearly half the participants did not recall such an explanation and $18 \%$ were also dissatisfied with the service they received, and these two variables were found to be linked (those who recalled an explanation were more likely to be satisfied with the service). Certainly, for some the process of registration was not one that they had expected or hoped for, and to this extent it may be somehow a symbolic moment. Registration often represents a point of profound change for someone: not only a time when their vision has deteriorated, but perhaps some realisation that it is unlikely to improve. Indeed, authors often identify blindness as being one of the most feared disabilities (e.g. Potter, 1993; Saaddine et al, 2003). However, even if it does not seem so at that time, the process of registration should ultimately be a positive action rather than a negative endpoint.

Importantly, in addition to the formal process of certification and registration there are other less standardised processes such as signposting patients to information and support services. Such services are present in many different configurations in some eye clinics in the UK and have a variety of titles such as 'help desks', 'eye clinic support services' and 'eye clinic liaison officers’ (e.g. see ADSS, 2002; Browne, 2002; Douglas, 2008; Sinclair and Ryan, 2008). There are clear advantages of such services - e.g. they are available at the time and in a location convenient for the patient, other eye clinic staff can refer patients on to people who have greater knowledge of social support services, and they can link patients to social support services quickly. Another important factor is that many patients will make repeated visits to eye clinics (demonstrated by the $50 \%$ of participants who had been registered in the preceding eight years reported currently attending eye clinics), and many attend low vision clinics (or have in the past). This provides multiple opportunities for people to seek appropriate support when they feel ready and as their needs and circumstances change. Some of the points raised by the participants highlight that relatively small and simple developments within the eye clinic could make big differences to what is a complex and challenging time for them.

Undoubtedly the survey approach adopted in this study has limitations in terms of what it can tell us about people's experiences within eye clinics. It is difficult (probably impossible) to make categorical links between survey findings and service practice and events. Participants 
were reflecting upon events which took place between 1999 and 2005 (up to 8 years prior to the interview) in relation to the complex and emotive process of certification of visual impairment. Studies have found that recall of information given during a medical consultation can be poor and deteriorates over time (McGuire, 1996). There are strategies designed to improve recall of medical advice which would be of interest to practitioners, and some of these may have particular relevance to visually impaired people who often have difficulty accessing print (e.g. the use of audio recordings). Watson and McKinstry (2009) present a review of impact of these approaches and offer helpful summaries (although they note that more research is required in the clinical setting). However, regardless of accuracy of recall, the findings from this representative sample give an important insight into what people who are registered visually impaired value and find difficult, what support they think is important, and how and when they think this support should be given. Aspinall et al (1999) highlight that patient satisfaction is a complex and multifaceted concept which must be interpreted carefully. However, we would argue that having an insight into peoples' understandings and reflections of when they were patients in the eye clinic is an important source of information. Those trying to develop services, and future research which seeks to prospectively evaluate services, might usefully consider some of the points raised here. 


\section{REFERENCES}

Anastas, J.W. (2004). Quality in Qualitative Evaluation: Issues and Possible Answers. Research on Social Work Practice, 14, 1, 57-65

Aspinall, P., Hill, A., Cotton, L. and McCloughan, C. (1999). Patient satisfaction at an evaluation measure of low vision services. British Journal of Visual Impairment, 17, 99-104.

Association of Directors of Social Services (ADSS) (2002). Progress in sight: national standards of social care for visually impaired adults. London: ADSS.

Browne, M. (2002). Patient support services in eye clinics: a nationwide survey. London : RNIB.

Bruce, I., McKennell, A., and Walker, E. (1991). Blind and partially sighted adults in Britain: the RNIB survey. London: HMSO.

Clements, B. and Douglas, G. (2009). Network 1000 Survey 1: Comparing the General and Registered Visually Impaired Populations. Peterborough: RNIB

Clements, B., Douglas, G. and Pavey, S. (2010). Which factors affect the chances of registered blind and partially sighted people in Britain being in paid employment? Submitted to: WORK: A Journal of Prevention, Assessment \& Rehabilitation.

Corcoran, C., Douglas, G., Pavey, S., Fielding, A., McLinden, M., McCall, S. (2004). Network 1000: the changing needs and circumstances of visually-impaired people: project overview. British Journal of Visual Impairment, September, 22, 3, 93-100.

Dale, S. (2008). Knitting in the dark narratives about the experience of sight loss in a counselling context. British Journal of Visual Impairment, 26, 269-278.

Department of Health (2003). Registered Blind and Partially Sighted People: Year ending 31 March 2003. London: Department of Health.

Douglas, G. (2008). Guidelines for keeping records of Eye Clinic Support Services (ECSS). London: Thomas Pocklington Trust, Good Practice Guide 2, May, 2008 http://www.pocklington-trust.org.uk/research/projects

Douglas, G., Corcoran, C, and Pavey, S. (2007). The role of the WHO ICF as a framework to interpret barriers to inclusion: visually impaired people's views and experiences of personal computers. British Journal of Visual Impairment, 25, 1, 32-50.

Douglas, G., Corcoran, C., and Pavey, S. (2006). Network 1000. Opinions and circumstances of visually impaired people in Great Britain: Report based on over 1000 interviews. Birmingham: Visual Impairment Centre for Teaching and Research, School of Education, University of Birmingham (mimeo). www.education.bham.ac.uk/research/VICTAR/research.shtml

Douglas, G. Pavey, S. and Corcoran, C. (2008). Finance and entitlement: Visually impaired people's take up of Disability Living Allowance and Attendance Allowance. University of 
Birmingham, February 2008. ISBN 0704426900 / 9780704426900.

http://www.education.bham.ac.uk/research/victar/research.shtml

Douglas, G., Pavey, S., Corcoran, C., and Brace, M. (2008). What do visually impaired people think is important? Responses from a survey of over 1000 visually impaired people in the UK. Proceedings of the 9th International Conference on Low Vision, Vision 2008, Montreal, Quebec, Canada. July 7 - 11, 2008

Duckett, P. S. and Pratt, R. (2001). The Researched Opinions on Research: visually impaired people and visual impairment research, Disability and Society, 16, 6, 815-835.

Fourie, J.F. (2007). A qualitative self-study of Retinitis Pigmentosa. British Journal of Visual Impairment, 25, 217-232.

Hammel J., Magasi S., Heinemann A.k Whiteneck G., Bogner J. and Rodriquez E. (2008). What does participation mean? An insider perspective from people with disabilities. Disability and Rehabilitation 30, 19, 1445-1460

Hendershot, G.E. and Crews, J.E (2006). Towards International Comparability of Survey Statistics on Visual Impairment: The DISTAB Project. Journal of Visual Impairment and Blindness, 100, 1, 11-25.

Low Vision Services Consensus Group (1999). Recommendations for future service delivery in the UK. London: RNIB.

Lussenhop, K. and A. L. Corn (2002). "Comparative studies of reading performance of students with low vision.” RE:view, 34, 2, 57-69.

Margrain, T. (2000). Helping blind and partially sighted people to read: the effectiveness of low vision aids. British Journal of Ophthalmology, 84, 919-921.

Martin, J., White, A. and Meltzer, H. (1989) Disabled Adults: services, transport and employment (London, HMSO).

McBride, S. (2001). Patients talking 2 - the eye clinic journey experienced by blind and partially sighted adults: a quantitative study. London: RNIB.

McGuire, L. C. (1996). Remembering What the Doctor Said: Organization and Adults' Memory for Medical Information. Experimental Aging Research, 22, 403-428.

Mitchell, J., Bradley, P., Anderson, S., ffytche, T. and Bradley, C. (2002). Perceived quality of health care in macular disease: a survey of members of the Macular Disease Society. British Journal of Ophthalmology, 86, 777-781.

NALSVI (2002). Taking local action: home partnerships between local societies and hospital eye clinics lead to improved services for people facing serious sight loss. Report of a conference at Stoke Mandeville Hospital celebrating 10 years of innovative work in linking health and social care for visually impaired people. National Association of Local Societies for Visually Impaired People. 
National Assembly for Wales (2003). SSDA900.1: Disability Register 2001-02, Version: 1 Released: 29/05/2003. Processed by the Local Government Data Unit - Wales.

Office for National Statistics (2008). Social and Vital Statistics Division, General Household Survey, 2006 [computer file]. 2nd Edition. Colchester, Essex: UK Data Archive [distributor], July 2008. SN: 5804.

Pavey, S., Douglas, G., and Corcoran, C. (2008). Transition into adulthood and work findings from Network 1000. British Journal of Visual Impairment, 26, 2, 202-216.

Pavey, S., Douglas, G. and Corcoran, C. (2005). Network 1000: A Guide to the Design and Content of the Year 1 Survey. Birmingham: University of Birmingham (mimeo). ISBN: 07044 25327. http://www.education.bham.ac.uk/research/victar/research.shtml

Pollard, T., Simpson, J., Lamoureux, E. and Keeffe, J. (2003). Barriers to accessing low vision services. Ophthalmic and Physiological Optics, 23, 321-327.

Potter, A.R. (1993). Editorial: Preventing blindness worldwide. BMJ, 309, 682-683.

Reeves, B.C., Harper R.A. and Russell, W.B. (2004). Enhanced low vision rehabilitation for people with age related macular degeneration: a randomised controlled trial. British Journal of Ophthalmology, 88, 1443-1449.

Robson, C. (2002). Real world research. 2nd edition. Blackwell publishing.

Saaddine, J.D., Narayan, V. and Vinicor, F. (2003). Editorial: Vision loss: a public health problem? Ophthalmology, 110. 2, 253-254

Sinclair, A. and Ryan, B. (2008). Low Vision - The Essential Guide for Ophthalmologists. The Guide Dogs for the Blind Association.

Scottish Executive (2003). Registration of Blind and Partially Sighted Persons 2003. Unpublished statistics.

Wallace, E. Paterson, H., Miller, S., Sinclair, A., Sanders, R. and Hinds, A. (2008). Patient profile and management in advanced glaucoma. British Journal of Visual Impairment, 26, 1, 7-23.

Watson, G.R., De L’Aune, W., Stelmack, J., Maino, J., and Long, S. (1997). National Survey of the Impact of Low Vision Device Use among Veterans. Optometry \& Vision Science, 74, 5, 249-259.

Watson, P.W.B. and McKinstry, B (2009). A systematic review of interventions to improve recall of medical advice in healthcare consultations. Journal of the Royal Society Medicine. 102, 235-243.

Williams, B., Copestake, P., Eversley, J. and Stafford, B. (2008), Experiences and Expectations of Disabled People: A Research Report for the Office for Disability Issues. London: Office for Disability Issues. 


\section{Acknowledgments}

The authors acknowledge funding from the Big Lottery Fund, VISION 2020 UK, RNIB, Thomas Pocklington Trust and GDBA.

The research was assessed and approved by University of Birmingham Ethics Committee (School of Education). The research was granted approval for a 'multi-site project' from the Association of Directors of Adult Social Services (ADASS, England and Wales) and the Association of Directors of Social Work (ADSW, Scotland) as well as receiving approval from relevant Local Authority Research Governance Framework Committees. 
Table 1: "Do you know the medical name of the eye condition that causes your eye sight problem?” (Prompted if required, prompt noted by researcher) Base: whole sample $(\mathrm{N}=960)$, weighted to account for population age distribution.

\begin{tabular}{|c|c|c|c|}
\hline & $\begin{array}{c}\text { Working age } \\
\%\end{array}$ & $\begin{array}{c}\text { Retirement age } \\
\%\end{array}$ & $\begin{array}{c}\text { Total } \\
\text { weighted } \\
\%\end{array}$ \\
\hline Macular degeneration & $9 \%$ & $59 \%$ & $49 \%$ \\
\hline Glaucoma & $10 \%$ & $20 \%$ & $18 \%$ \\
\hline Cataract & $9 \%$ & $16 \%$ & $15 \%$ \\
\hline Diabetic related & $9 \%$ & $5 \%$ & $5 \%$ \\
\hline Retinitis pigmentosa & $12 \%$ & $2 \%$ & $4 \%$ \\
\hline Injury & $4 \%$ & $2 \%$ & $2 \%$ \\
\hline Detached retina & $4 \%$ & $3 \%$ & $4 \%$ \\
\hline Other & $57 \%$ & $26 \%$ & $32 \%$ \\
\hline Don't know & $13 \%$ & $11 \%$ & $11 \%$ \\
\hline Number interviewed & 563 & 397 & 960 \\
\hline
\end{tabular}

Note: This analysis excludes 'key participants' who were interviewed on behalf of 47 visually impaired participants with communication or learning disabilities for whom the interview was not appropriate. 
Table 2: Post-hoc analysis by authors who interpreted the descriptions of visual condition provided by 581 participants $(43 \%)$ who either did not know the name of their condition or reported their condition as 'other'. Weighted.

\begin{tabular}{|c|c|c|c|}
\hline & $\begin{array}{c}\text { Working age } \\
\%\end{array}$ & $\begin{array}{c}\text { Retirement age } \\
\%\end{array}$ & $\begin{array}{c}\text { Total } \\
\text { weighted } \\
\%\end{array}$ \\
\hline \multicolumn{4}{|l|}{ Field loss } \\
\hline Related to stroke/tumour & $8 \%$ & $4 \%$ & $5 \%$ \\
\hline General & $6 \%$ & $3 \%$ & $4 \%$ \\
\hline \multicolumn{4}{|l|}{ Anterior eye disease } \\
\hline Uveitis & $3 \%$ & $1 \%$ & $1 \%$ \\
\hline Aniridia & $2 \%$ & $1 \%$ & $2 \%$ \\
\hline Corneal & $1 \%$ & $4 \%$ & $3 \%$ \\
\hline \multicolumn{4}{|l|}{ Optic atrophy } \\
\hline Leber's amaurosis & $3 \%$ & $0 \%$ & $1 \%$ \\
\hline Tumour & $5 \%$ & $2 \%$ & $3 \%$ \\
\hline General & $9 \%$ & $2 \%$ & $5 \%$ \\
\hline \multicolumn{4}{|l|}{ Other } \\
\hline High myopia & $6 \%$ & $6 \%$ & $6 \%$ \\
\hline Other retinal & $17 \%$ & $15 \%$ & $15 \%$ \\
\hline Nystagmus & $11 \%$ & $1 \%$ & $4 \%$ \\
\hline Ocular albinism & $4 \%$ & $0 \%$ & $1 \%$ \\
\hline Retinoblastoma & $1 \%$ & $0 \%$ & $0 \%$ \\
\hline Other eye conditions & $6 \%$ & $5 \%$ & $5 \%$ \\
\hline Unclear and don't know & $9 \%$ & $12 \%$ & $11 \%$ \\
\hline Number interviewed & 416 & 165 & 581 \\
\hline
\end{tabular}


Table 3: "Do you have any long-standing illness or disability" a Base: Network 1000, whole sample ( $\mathrm{N}=960)$, weighted; General Household Survey, whole sample $(\mathrm{N}=17642)$, weighted.

\begin{tabular}{|l|c|c|c|c|c|}
\hline & $\begin{array}{c}18-29 \\
(\%)\end{array}$ & $\begin{array}{c}30-49 \\
(\%)\end{array}$ & $\begin{array}{c}50-64 \\
(\%)\end{array}$ & $\begin{array}{c}65-74 \\
(\%)\end{array}$ & $\begin{array}{c}75+ \\
(\%)\end{array}$ \\
\hline General Population $^{\mathrm{b}}$ & $15 \%$ & $25 \%$ & $45 \%$ & $61 \%$ & $68 \%$ \\
\hline Network 1000 & $46 \%$ & $46 \%$ & $68 \%$ & $73 \%$ & $73 \%$ \\
\hline
\end{tabular}

${ }^{\text {a }}$ For Network 1000 survey the question also included "in addition to your visual impairment"

b Source: General Household Survey 2006 (ONS, 2008). 
Table 4: "Do you use magnifiers for reading?” (Prompted). Base: whole sample, excluding participants who reported having no light perception $(\mathrm{N}=907)$, weighted.

\begin{tabular}{|c|c|c|c|}
\hline & $\begin{array}{l}\text { Working age } \\
\%\end{array}$ & $\begin{array}{l}\text { Retirement } \\
\text { age } \\
\%\end{array}$ & $\begin{array}{c}\text { Total } \\
\text { weighted } \\
\%\end{array}$ \\
\hline Use a magnifier for reading: & $64 \%$ & $72 \%$ & $70.7 \%$ \\
\hline $\begin{array}{r}\text { Hand-held magnifier (with or without a } \\
\text { light) }\end{array}$ & $53 \%$ & $66 \%$ & $63 \%$ \\
\hline Stand magnifier (with or without a light) & $6 \%$ & $9 \%$ & $9 \%$ \\
\hline $\begin{array}{r}\text { Magnifier attached to or mounted on } \\
\text { spectacles }\end{array}$ & $7 \%$ & $5 \%$ & $5 \%$ \\
\hline CCTV & $15 \%$ & $14 \%$ & $14 \%$ \\
\hline Other & $16 \%$ & $15 \%$ & $15 \%$ \\
\hline Do not use (and have never tried) & $14 \%$ & $5 \%$ & $6.7 \%$ \\
\hline Do not use (but have tried in the past) & $22 \%$ & $23 \%$ & $22.7 \%$ \\
\hline Number interviewed & 522 & 385 & 907 \\
\hline
\end{tabular}


Table 5: "What kind of help/information was offered in the eye clinic at time of first certification as blind or partially sighted?" (Prompted) Base: those registered within the previous 8 years $(\mathrm{N}=395)$, weighted.

\begin{tabular}{|r|c|c|c|}
\hline & $\begin{array}{c}\text { Working Age } \\
\%\end{array}$ & $\begin{array}{c}\text { Retirement } \\
\text { Age } \\
\%\end{array}$ & $\begin{array}{c}\text { Total } \\
\text { weighted } \\
\%\end{array}$ \\
\hline Explanation of the registration process & $41 \%$ & $49 \%$ & $48 \%$ \\
Information on talking books & $31 \%$ & $49 \%$ & $46 \%$ \\
Information on any low vision aids (LVAs) & $40 \%$ & $45 \%$ & $45 \%$ \\
General information about social services & $36 \%$ & $44 \%$ & $43 \%$ \\
Information on helpful gadgets and equipment & $30 \%$ & $39 \%$ & $38 \%$ \\
\hline Leaflets about your visual impairment & $31 \%$ & $35 \%$ & $35 \%$ \\
Specific contact details for social services & $28 \%$ & $26 \%$ & $26 \%$ \\
\hline Details of any voluntary organisations & $37 \%$ & $23 \%$ & $25 \%$ \\
\hline Details of a home worker/carer services & $12 \%$ & $16 \%$ & $15 \%$ \\
Appropriate information to help the family & $14 \%$ & $9 \%$ & $10 \%$ \\
\hline Counselling either at the time or later & $9 \%$ & $7 \%$ & $8 \%$ \\
Any nutritional advice & $6 \%$ & $6 \%$ & $6 \%$ \\
Other & $2 \%$ & $4 \%$ & $4 \%$ \\
\hline Nothing & $32 \%$ & $15 \%$ & $17 \%$ \\
\hline Don't know & $1 \%$ & $2 \%$ & $2 \%$ \\
\hline Can't remember & $3 \%$ & $4 \%$ & $4 \%$ \\
\hline Number interviewed & 183 & 212 & 395 \\
\hline & & & \\
\hline
\end{tabular}

